acute leukaemia, but some intrapulmonary bleeding was identified in half. They reported also that one-third of all fatal haemorrhages in leukaemia occurred in the lungs. ${ }^{13}$ Leach $^{14}$ found that pulmonary haemorrhage was the direct cause of death in three out of 157 cases of acute leukaemia. Pulmonary infiltrates and associated symptoms were observed in over $30 \%$ of a large series of children with acute lymphocytic leukaemia. Despite aggressive attempts at diagnosis the cause of the pulmonary process was determined in less than a quarter of the cases. ${ }^{15}$

We suggest that intrapulmonary bleeding may often cause radiographic abnormalities in patients with leukaemia. Bronchopulmonary lavage offers a safe approach to diagnosis in these cases, and alveolar macrophage staining for haemosiderin and haemoglobin may be useful in determining whether a recent bleed has occurred. When infection and haemorrhage are both present the lavage procedure may also allow identification of an infectious agent. The technique may provide evidence for pulmonic haemorrhage but may not delineate the cause. For example, pulmonary embolism occurring in leukaemic patients ${ }^{16}$ might lead to similar findings at bronchopulmonary lavage.

We thank Lisken Byers and Ann Sullivan for excellent technical help.

This study was supported in part by a grant from the California Lung Association, United States Public Health Service grant CA 15688, and a grant from Brown and Williamson Tobacco Corporation,
Philip Morris Incorporated, R. J. Reynolds Tobacco Company, U.S. Tobacco Company, and Tobacco Associates, Incorporated.

Requests for reprints should be addressed to Dr. David W. Golde.

\section{References}

1 Bodey, G. P., et al., Cancer, 1966, 19, 781.

2 Sickles, E. A., et al., Annals of Internal Medicine, 1973, 79, 528.

3 Levine, A. S., et al., Seminars in Hematology, 1974, 11, 141 .

4 Drew, W. L., et al., Fournal of the American Medical Association, 1974, 230, 713.

${ }^{5}$ Fennessy, J. J., and Kittle, C. F., fournal of Thoracic and Cardiovascular

Surgery, 1973, 66, 541 .
${ }^{6}$ Whitecar, J. P., jun., et al., Cancer Chemotherapy Reports, pt. I, 1972, 56,

543.
${ }^{7}$ Finley, T. N., and Ladman, A. J., New England Fournal of Medicine, 1972, 286, 223.

8 Golde, D. W., Finley, T. N., and Cline, M. J., Lancet, 1972, 2, 1397.

Bowling, M. C., Histopathology Laboratory Procedures of the Pathologic Anatomy Branch of the National Cancer Institute. Public Health Service 1967.

10 Golde, D. W., Byers, L. A., and Finley, T. N., Nature, 1974, 247, 373.

11 Golde, D. W., Finley, T. N., and Cline, M. J., New England fournal of Medicine, 1974 iney, $\mathrm{T}$.

12 Blank, N., Castellino, R. A., and Shah, V., Radiologic Clinics of North America, 1973, 11, 175 .

13 Hersh, E. M., et al., fournal of the American Medical Association, 1965, 193, 105

${ }_{14}$ Leach, W. B., Canadian Medical Association fournal, 1961, 85, 345.

15 Siegel, S. E., Baehner, R., and Nesbit, M., American Society of Hematology Seventeenth Annual Meeting, 1974, Abstract no. 378, p. 171.

16 Wiernik, P. H., and Serpick, A. A., Cancer, 1969, 24, 581.

\title{
Gastro-oesophageal Reflux Complicating Highly Selective Vagotomy
}

\author{
J. G. TEMPLE, JOHN MCFARLAND
}

British Medical fournal, 1975, 2, 168-169

\section{Summary}

An unacceptably high incidence of gastro-oesophageal reflux was observed in a small series of patients with duodenal ulcer who had been treated by highly selective vagotomy. Possibly this is due to an altered angle of entry of the oesophagus into the stomach, and we now routinely narrow this angle at operation.

\section{Introduction}

Highly selective vagotomy (H.S.V.) without drainage is rapidly gaining acceptance in the treatment of uncomplicated chronic duodenal ulceration. It is claimed that a more normal pattern of gastric emptying is preserved and that the incidence of postvagotomy sequelae, such as dumping, diarrhoea, and bilious vomiting, is greatly reduced.1 ${ }^{2}$ Furthermore, an exhaustive review $^{3}$ has shown that in the Leeds and Copenhagen series side effects, such as dysphagia, flatulence, and heartburn, were no more common after H.S.V. than after vagotomy with a drainage procedure.

\section{Royal Southern Hospital, Liverpool L8 5SH}

J. G. TEMPLE, M.B., F.R.C.S., Senior Registrar in Surgery (Present appointment: Senior Lecturer in Surgery, Manchester University, Hope Hospital,

Salford)
J. B. McFARLAND, CH.M., F.R.c.s., Consultant Surgeon

We encountered severe and persistent oesophageal reflux in five of a small series of patients with chronic duodenal ulceration who were treated by H.S.V. without drainage in our unit.

\section{Patients and Methods}

Twenty parients with chronic duodenal ulceration and no clinical or radiological evidence of pyloric stenosis, gastro-oesophageal reflux, or hiatus hernia underwent H.S.V. At operation the diagnosis was confirmed and pyloric stenosis and hiatus hernia excluded. All the operations were performed by one of us (J.M.). The surgical technique was standard, ${ }^{4}$ the denervation being started at a point just to the left of the terminal branches of the nerves of Latarjet (6-7 cm from the pyloroduodenal junction). All the patients were followed up regularly for at least two years. Acidoutput studies were performed before and three months after the operation. Interpretation of the insulin response was based on Hollander's $s^{5}$ original oriteria with the addition of a second one-hour collection period. The results were classified as negative, early positive (0-60 $\mathrm{min})$, and late positive $(60-120 \mathrm{~min})$.

\section{Results}

Though only 20 patients were treated in this pilot series we were disturbed to find that five developed persistent symptoms of gastro-oesophageal reflux. The typical features of gastrooesophageal reflux-heartburn, retrosternal discomfont, and regurgitation, accompanied by increased flatulence-developed shortly after surgery in three of the patients and between six to 12 months after in the other two (see table). A postoperative barium meal examination showed gastro-oesophageal reflux in four of the patients, with evidence of a hiatus hernia in three. Though reflux could not be shown radiologically in the other patient a 
slight hold-up of the barium at the lower end of the oesophagus was seen, which could have indicated spasm due to some oesophagitis as his symptoms were particularly severe at the time of the examination. As in the preoperative examination all the patients had normal gastric emptying after the barium meal. Their symptoms were sufficient to require constant medication and all five patients were classified as grade III on the Visick scale. ${ }^{6}$

The insulin test was positive in four of these patients, which corresponds well with our finding that 12 of the 17 patients who had been insulin tested at the time of writing were insulin postitive.

Symptoms and Radiological Findings in Five Patients with Gastro-oesophageal Reflux

\begin{tabular}{|c|c|c|c|c|c|}
\hline $\begin{array}{l}\text { Case } \\
\text { No. }\end{array}$ & $\begin{array}{l}\text { Age } \\
\text { and } \\
\text { Sex }\end{array}$ & $\begin{array}{l}\text { History } \\
\text { of } \\
\text { Ulcer } \\
\text { (Years) }\end{array}$ & $\begin{array}{c}\text { Time of } \\
\text { Appearance } \\
\text { of Symptoms } \\
\text { after } \\
\text { Operation }\end{array}$ & Symptoms & $\begin{array}{c}\text { Barium Meal } \\
X \text {-Ray Findings }\end{array}$ \\
\hline$\frac{1}{2}$ & $\begin{array}{l}49 \mathrm{M} \text {. } \\
44 \mathrm{M} \text {. }\end{array}$ & $\begin{array}{r}6 \\
10\end{array}$ & $\begin{array}{l}12 \text { months } \\
\text { Very soon }\end{array}$ & $\begin{array}{l}\text { Heartburn, flatulence } \\
\text { Heartburn, flatulence }\end{array}$ & $\begin{array}{l}\text { Hiatus hernia, reflux } \\
\text { Slight delay in lower } \\
\text { end of oesophagus }\end{array}$ \\
\hline 3 & $56 \mathrm{M}$. & 14 & 6 months & Heartburn, acid & Hitaus hernia, \\
\hline 4 & $50 \mathrm{~F}$. & 30 & Immediately & $\begin{array}{l}\text { Nausea, epigastric } \\
\text { discomfort, heart- } \\
\text { burn, flatulence }\end{array}$ & $\begin{array}{l}\text { Hiatus hernia, } \\
\text { oesophageal reflux }\end{array}$ \\
\hline 5 & $41 \mathrm{~F}$. & 6 & 3 months & $\begin{array}{l}\text { Heartburn, acid } \\
\text { regurgitation }\end{array}$ & Oesophageal reflux \\
\hline
\end{tabular}

\section{Discussion}

There is a definite incidence of gastro-oesophageal reflux after truncal vagotomy, but it is persistent in only $7 \%$ of cases and severe in only $1.5 \% .{ }^{7}$ We are unaware of any reports of this problem after H.S.V. without drainage yet we found that in five out of 20 patients this operation resulted in persistent troublesome reflux. How can this be explained?

Reflux after truncal vagotomy is thought to result from weakening of the lower intrinsic oesophageal sphincter rather than disturbance of the normal anatomical relationship at the gastrooesophageal junction. ${ }^{8}$ The fact that the incidence of reflux is no less after transthoracic vagotomy supports this theory. ${ }^{\circ}$ Thomas and Earlam ${ }^{10}$ have shown that the length of the zone of increased pressure at the gastro-oesophageal junction is decreased after truncal vagotomy with drainage, though there is no lessening of the pressure itself in this region, as there is after gastrectomy. Griffith and Harkins ${ }^{11}$ suggested that the technique of selective vagotomy may actually prevent oesophageal damage and denervation, and they considered that malfunction of the lower oesophageal sphincter was caused by division of terminal filaments of the vagus as they enter the oesophageal muscle. Certainly H.S.V. does not involve any greater mobilization of the paraoesophageal vagal trunks than does truncal vagotomy. Indeed, there should be less interference in this area. Possibly, as a result of the greater mobilization of the stomach which is necessary in this operation a degree of gravitational dependence develops which may alter slightly the angle of entry of the oesophagus into the stomach. Such a mechanism has been suggested by Windsor ${ }^{12}$ to account for the greater degree of reflux seen after Billroth I gastrectomy compared with the Polya operation. Alternatively, even the most limited and careful dissection in the region of the intra-abdominal oesophagus may be sufficient to damage the small vagal fibres which supply the lower oesophageal area. Certainly, the possibility that the trouble arises at this point cannot be discounted.

Might some inadequacy in the gastric emptying mechanism play a part? This mechanism seemed to be normal in our patient when tested by barium meal radiography, but this is not a very sensitive test. Total vagotomy without drainage certainly causes inadequate emptying, which leads to gastric distension and oesophageal regurgitation in many but not all cases. ${ }^{13}$ Similarly, selective vagotomy alone, with only the innervation of the pyloric sphincter intact, causes an unacceptably high incidence of gastric stasis ${ }^{14}$ in spite of earlier reports to the contrary. ${ }^{15}$ The current trend is to leave some $10-11 \mathrm{~cm}$ from the pyloric sphincter innervated, rather than $7 \mathrm{~cm}$ as done formerly, ${ }^{4}$ but it seems possible that the object of the operation could be vitiated by excessive preservation of gastric innervation. The point to which innervation is taken may be quite critical.

We are forced to conclude that though minor differences in technique affecting either the oesophagogastric junction or the distal point of denervation may not cause problems individually, together they may lead to just the sort of trouble that has been observed in these cases. Moreover, it may prove difficult to define and work to technical tolerance limits, which may be more critical than has been appreciated. Can anything be done to minimize the adverse effect we have described?

Since making these observations it has been our practice to narrow the angle of His by opposing the stomach to the oesophagus with a continuous chromic catgut stitch run up for about $5 \mathrm{~cm}$ from the oesophagogastric junction. This simple procedure, which has been used by Hollender ${ }^{16}$ in 76 patients undergoing H.S.V., may readily be added when small vagal fibres are being cleared from the area.

\section{References}

1 Humphrey, C. S., and Wilkinson, A. R., British fournal of Surgery, 1972, 59, 779.

2 Johnston, D., et al., Gut, 1972, 13, 842.

8 Johnston, D., Gut, 1974, 15, 748.

Goligher, J. C., British fournal of Surgery, 1974, 61, 337.

Hollander, F., Gastroenterology, 1948, 11, 419.

6 Goligher, J. C., Pulvertaft, C. N., and Watkinson, G., British Medical fournal, J964, Pulvertaf

7 Wournal, 1964, 1, 455.

illiams, J. A., and Woodward, D. A. K., Surgical Clinics of North America, 1967, 47, 1341.

Williams, J. A., and Cox, A. G., After Vagotomy, p. 42. Butterworth,

- Grimson, K. S., et al., fournal of the American Medical Association, 1947, 134, 925.

10 Thomas, P. A., and Earlam, R. J., British fournal of Surgery, 1973, 60, 717. Griffiths, C. A., and Harkins, N. H., Surgical Clinics of North America,

12 Windsor, C. W. O., British Medical fournal, 1964, 2, 1233.

13 Dragstedt, L. R., et al., Annals of Surgery, 1947, 126, 687.

14 Clarke, R. J., McFarland, J. B., and Williams, J. A., British Medical Fournal, 1972, 1, 538.

15 Burge, H., et al., British Medical fournal, 1969, 3, 690.

16 Hollender, L. F., Fournal de Chirurgie, 1973, 106, 379. 